\title{
Effects of ozone applied by spinal endoscopy in patients with chronic pain related to failed back surgery syndrome: a pilot study
}

This article was published in the following Dove Press journal:

Neuropsychiatric Disease and Treatment

12 November 2013

Number of times this article has been viewed

\section{Francisco Nêuton de Oliveira Magalhães Sandra Correia Soares Jaqueline Melo Torres Arthur Ungaretti Mariana Fillipi Cacciacarro Manoel Jacobsen Teixeira Erich Talamoni Fonoff}

Pain Center and Division of Functional Neurosurgery, Department of Neurology, School of Medicine, University of São Paulo, São Paulo, Brazil
Correspondence: Erich Talamoni Fonoff Division of Functional Neurosurgery, Hospital das Clínicas, University of São Paulo, Rua Dr Ovídio Pires de Campos, 785, São Paulo, SP, Brazil 01060-970

Tel +55 II $266 \mid 6402$

Fax +55 I| $266 \mid 6402$

Email fonoffet@usp.br
Introduction: In the last two decades, ozone has emerged as a treatment for low back pain, applied by means of minimally invasive techniques.

Objective: The aim of this study is to assess the effect and safety of ozone therapy applied in the epidural space for chronic pain related to failed back surgery syndrome.

Methods: The investigators studied 13 sequential patients of both sexes, between 18 and 70 years old, with persistent chronic pain (more than six months) in the lumbar region and in the lower limbs related to failed back surgery syndrome (FBSS). Pain was classified as neuropathic and non-neuropathic regarding the topography (lumbar and lower limb), based on the DN4 (Douleur Neuropathique 4) questionnaire. The patients received the ozone gas in the lumbar epidural space via spinal-sacral endoscopy. Clinical evaluation was performed before, immediately after (24 hours), and 1, 3, and 6 months after intervention with visual analog scale and Oswestry Disability Index (ODI).

Results: Overall, the patients had $43.7 \%$ reduction of lumbar pain, $60.9 \%$ reduction in leg pain in six months followed by $44.0 \%$ of improvement in ODI. The reduction of pain and in the disability index was markedly greater in patients with non-neuropathic predominant pain, 95.2\%, 80.6\%, and 75.3\% improvement in lumbar, leg pain, and ODI respectively, while neuropathic predominant pain patients experienced only $12.5 \%, 42.4 \%$, and $20.9 \%$ improvement, also respectively. No neurological or infectious complications were observed acutely or during the follow-up. The present data suggests that epidural ozone might be a therapeutic option for persistent low back pain, especially in non-neuropathic predominant pain patients, but doubleblind controlled studies are still required to prove its efficacy.

Keywords: pain, failed back surgery syndrome, neuropathic pain, epiduroscopy, spinal endoscopy, ozone, minimally invasive surgery

\section{Introduction}

Chronic pain, along with immeasurable suffering, can cause functional limitation in about $5 \%$ of the general population. ${ }^{1-3}$ Low back pain occurs in more than half of the adult population and in most cases tends to be chronic and persistent. ${ }^{4,5}$ Between $40 \%$ and $80 \%$ of patients undergoing back surgery continue to experience persistent pain, a condition called "failed back surgery syndrome" (FBSS). ${ }^{6}$ The symptoms of FBSS include persistent or recurring low back and/or leg pain after one or more spinal operations. ${ }^{6}$ The precise cause of the pain can be difficult to determine in each patient, due to the complex interaction of biological and psychosocial aspects. ${ }^{3}$ Possible organic causes of FBSS include: epidural fibrosis; arachnoiditis; mechanical factors; inflammationinduced changes in the nerve roots; structural changes in the vertebral column; and lumbar degenerative disease. ${ }^{6,7}$ Pain in these cases includes a neuropathic component, 
but a nociceptive or inflammatory constituent may coexist in the same patient. ${ }^{3}$ After a second surgical intervention, the failure rate can be as high as $65 \%-70 \%$, with $15 \%-20 \%$ of patients reporting worsening of symptoms. Thus, repeated surgery tends to yield poorer results. ${ }^{6}$

Epidural ozone injection has emerged as an additional treatment option for those patients who would otherwise require additional open surgery. ${ }^{8}$ Despite its wide use for the treatment of a variety of conditions, ozone therapy is still unknown to most physicians. Observational studies using intradiscal or intraforaminal ozone therapy in patients with FBSS showed positive results in alleviating low back pain in between $44 \%$ and $81 \%$ of patients. ${ }^{9}$ However, observational studies have generally evaluated heterogeneous populations of patients with low back pain containing only some patients with FBSS. ${ }^{10-12}$ Recently, a systematic review and meta-analysis on the effects of ozone therapy for low back pain secondary to herniated disc indicated a level of evidence of II-3 for ozone therapy applied intradiscally and of II-1 for ozone therapy applied at the paravertebral muscle and periforaminally for longterm pain relief. ${ }^{9}$ The low costs of ozone therapy may account for its potential broader use in the future. Guided by percutaneous approaches, injections can be repeated if necessary and complications or side effects are rare. ${ }^{9}$ Although more detailed analyses must be conducted in order to determine its effectiveness, epidural, intradiscal, or periforaminal delivery of ozone are being considered as options for treating lumbar disc herniation-related pain that fails to respond to conservative treatment, representing an alternative to surgery in some cases. ${ }^{9,13,14}$

Generally, good results in the treatment of chronic pain are only obtained in a limited number of patients, and it is difficult to determine which patients will have a good outcome. Prediction factors may vary in type and complexity, ranging from simple symptom rating by clinical scales to expensive image studies or biological and genetic markers. A classification of types of pain has been proposed by the DN4 (Douleur Neuropathique 4) clinical scale, based on symptom, in various populations..$^{15}$ This instrument promotes a basic symptom rating likely to be present in neuropathic pain syndromes and reliably suggests who is more likely to present neuropathic or inflammatory pain, or both, determining the predominant component when the two are present. ${ }^{15}$ In low back pain, ${ }^{16}$ as well as in FBSS, ${ }^{3}$ both types of pain seem to coexist in the same patients, but can be identified by this scale.

In this context, the authors report the initial experience of epidural injections of ozone therapy by spinal endoscopy in a small series of patients with FBSS. Although an overall improvement in pain was observed, interesting results were found when the analysis took into account the type of pain determined by the DN4 neuropathic pain scale, even after 6 months of follow-up.

\section{Materials and methods \\ Patients}

This study included 13 sequential patients of both sexes, aged between 18 and 70 years, with previous history of chronic pain treated by operation for lumbar disc herniation. None of the patients had experienced improved symptoms after the surgical procedure. The following inclusion and exclusion criteria applied. Inclusion criteria comprised: sciatic pain with at least 5 points in visual analog scale (VAS); previous lumbar spine surgery; more than 6 months with pain refractory to medical and rehabilitation treatment; no residual root compression in image studies; patients without a labor dispute or secondary gain from the presense of pain. Patients were excluded from the study if they were unable to fill out the questionnaire (Oswestry Disability Index $[\mathrm{ODI}]^{17}$ ) or presented with any of the following: any other spinal disease or spinal mechanical instability; allergy to ozone; use of oral anticoagulants; an identified cause of pain other than FBSS; favism (significant glucose-6-phosphate-dehydrogenase deficit); hyperthyroidism (ie, any contraindication for ozone therapy).

Patients were evaluated by general and neurological examination, followed by image studies (lumbosacral magnetic resonance imaging [MRI] and dynamic plain radiography). The pain was classified as neuropathic or nonneuropathic based on the DN4 questionnaire. ${ }^{18}$ Regarding the topography of pain, this was classified either in lumbar or in the lower limb as separate clinical entities. Clinical outcome was evaluated with VAS at baseline and at 24 hours and 1, 3 , and 6 months after the procedure. ODI score was also calculated at baseline and at 1,3, and 6 months of follow-up. Additionally, oral medication was quantified for the entire follow-up.

The survey of possible side effects or adverse events of epiduroscopy and the ozone therapy was done through a structured questionnaire, which was drawn from a literature review, ${ }^{19,20}$ and analyzed according to the terminology of the Common Terminology Criteria for Adverse Events, Version 4.0, 2006 (http://evs.nci.nih.gov/ftp1/CTCAE/About.html).

All patients were informed of the potential risks of treatment. Written informed consent was obtained from each subject, according to the approval of the ethics committee of 
the Hospital das Clínicas of the School of Medicine, University of São Paulo, São Paulo, Brazil.

\section{Methods}

Spinal endoscopy was carried out under local anesthesia with the patient awake, thus avoiding potential unrecognized pressure effects in the epidural canal. Light sedation and analgesia were sometimes required to ensure full patient cooperation while maintaining verbal contact. The patients were positioned prone with a pillow under their hips. The procedure was performed under aseptic conditions with antibiotic prophylaxis and required the use of fluoroscopy. Sacrococcygeal ligament puncture was made with a $17 \mathrm{~g}$ Tuohy needle and was followed by a caudal epidurogram to confirm needle placement. Subsequently, the Seldinger technique was performed for dilator placement and inserter sheaths were inserted through a small incision. Next, a fiber-optic microendoscope (Flexible Fiber Optic Endoscope - Model 3000E; Myelotec ${ }^{\circledR}$, Roswell, GA, USA) was introduced into the epidural space through the introducer, by which to obtain video images. A microendoscope (0.9 mm in diameter) was placed with its tip at the end of a steerable,

Table I Demographic characteristics of patient population: sex, age, duration of pain, previous procedures, working status, neurologic deficits, and classification of pain according to DN4 ${ }^{15}$

\begin{tabular}{ll}
\hline Demographic characteristic & $\mathbf{n}(\%)^{\mathbf{a}}$ \\
\hline Male sex & $6(45.1)$ \\
Female sex & $7(53.8)$ \\
Mean age, years (SD) & $52.2(10)$ \\
Duration of pain, years & \\
$<$ I & 0 \\
I-4 & 1 \\
$5-10$ & 7 \\
$\geq 10$ & 5 \\
Number of previous surgical procedures & \\
I & $6(45.1)$ \\
2 & $3(42.8)$ \\
3 & $1(7.6)$ \\
4 & $1(7.6)$ \\
Work status & \\
Unemployed & $4(30.7)$ \\
Retired & $6(46.1)$ \\
In litigation & $5(38.4)$ \\
Working & $2(15.3)$ \\
Neurologic deficits & \\
Sensitive impairment & $10(76.9)$ \\
Motor impairment & $8(61.53)$ \\
Neuropathic pain component (according to DN4) & \\
Yes & 6 \\
No & 7 \\
\hline Notes Excep whe ind a & \\
\hline
\end{tabular}

Notes: ${ }^{a}$ Except where indicated otherwise; ${ }^{b}$ there was some overlap between unemployed patients and patients in litigation.

Abbreviations: SD, standard deviation; DN4, Douleur Neuropathique 4. video-guided catheter (VG 2010, Myelotec $^{\circledR}$ ). Slow irrigation with saline allowed visualization of the epidural space by gentle distension. Blunt dissection coupled with hydrostatic distension of the epidural space thus created a pocket through which injected drug could access symptomatic nerve roots. ${ }^{21}$ After adhesiolysis, patients received $20 \mathrm{~mL}$ oxygen-ozone mixture at a concentration of $30 \mu \mathrm{g} / \mathrm{mL}$, obtained from an ozone generator (Medplus Philozon ${ }^{\circledR}$, Balneário Camboriu, $\mathrm{SC}$, Brazil). After the procedure, the patient was left at rest for 2 to 4 hours in the supine position and then discharged from the hospital.

\section{Results}

The demographic characteristics of patients are shown in Table 1. The patients had pain in the distribution of dermatomes L5 and S1, or both, associated with motor and sensory alterations.

All patients had some degree of pain reduction after the procedure. However, the reduction was greater in patients with a predominantly non-neuropathic component. Regarding the use of analgesic drugs, during follow-up, 4/13 patients had stopped taking analgesics, $5 / 13$ patients had had a significant reduction of oral medication, and 4/13 patients had continued with the same dose of drugs.

Overall, the patients had a $43.7 \%$ reduction of lumbar pain and a $60.9 \%$ reduction in leg pain, with a $44.0 \%$ of improvement in ODI scores after 6 months. The reduction of pain and improvement in the disability index was markedly greater in patients with predominantly non-neuropathic pain, with a $95.2 \%, 80.6 \%$, and $75.3 \%$ improvement in lumbar, leg pain, and ODI, respectively, while predominantly neuropathic pain patients experienced only a $12.5 \%, 42.4 \%$, and $20.9 \%$ improvement, respectively (see Figures 1-3).

No permanent neurological signs, cerebrospinal fluid leak, or infectious complications were observed during the follow-up period. However, one patient had transient paraesthesias in the lower limbs during application of ozone that lasted for a few minutes and one patient complained of headache for 24 hours after the procedure.

\section{Discussion}

There are several treatment modalities for patients with FBSS, from medication and physical therapy, psychological counseling, interventional procedures such as spinal cord stimulation, reoperation with or without vertebral arthrodesis, and minimally invasive percutaneous procedures. ${ }^{22}$ In the last decade, some procedures have been developed that may allow the direct application of drugs to nerves or other 


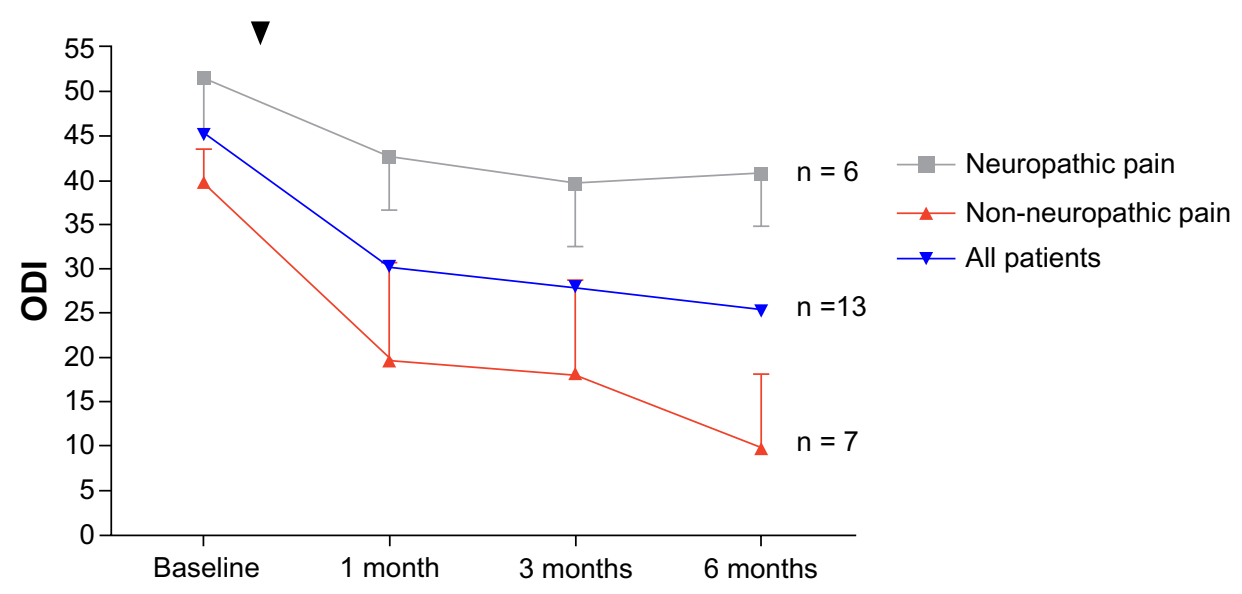

Follow-up

Figure I Median score of the Oswestry Disability Index (ODI) questionnaire ${ }^{17}$ according to the time of evaluation before and after the procedure ( $\left.\nabla\right)$.

Notes: There was no significant difference between the groups, but both groups showed improvement with significant difference at 6 months of follow-up compared to baseline.

tissues responsible for the origin of nociceptive stimuli in order to decrease or eliminate adhesions (or fibrosis) and thus eliminate its deleterious effect. This can be done not only through percutaneous techniques guided by fluoroscopy or computed tomography (CT), but also by endoscopy (epiduroscopy). ${ }^{13}$

In 2009, a systematic review on endoscopic adhesiolysis in the treatment of patients with FBSS indicated positive results with evidence level II-1 or II-2 based on US Preventive Services Task Force (USPSTF) criteria, and also based in one randomized trial with a recommendation of $1 \mathrm{C} /$ strong recommendation. Local anesthesic and glucocorticoid steroid were applied following mechanical spinal endoscopic adhesiolysis in all studies included in the analysis in this systematic review. Clonidine and bovine hyaluronidase were additionally applied in two studies included in this review. ${ }^{13}$

In the last two decades, particularly in Europe, many authors have been devoted to the study of ozone as a treatment for low back pain, applied by means of minimally invasive techniques such as paravertebral, intradiscal, and periradicular injections. ${ }^{23,24}$ Hence, our group performed a systematic review of the literature with meta-analysis to evaluate the therapeutic results of percutaneous injection of ozone for low back pain secondary to disc herniation. The outcome measure was short-term pain relief of at least 6 months or long-term

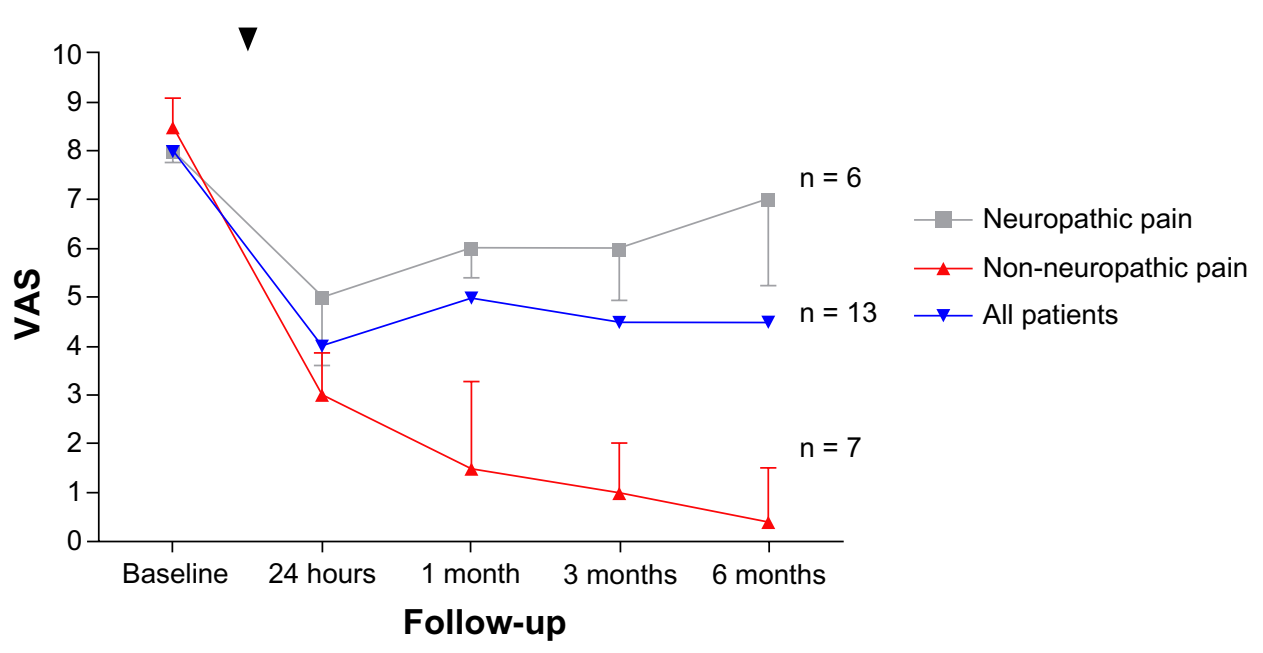

Figure 2 Median visual analog scale (VAS) scores in the lumbar region according to the time of evaluation before and after the procedure ( $\nabla$ ).

Notes: There was significant difference between the groups at 3 and 6 months $(P=0.003$ and $P=0.007$, respectively). Both groups showed significant improvement, but the group with non-neuropathic pain showed better results at the beginning, while the neuropathic pain group improved in the first 24 hours but lost the benefit in pain scores toward the end of follow-up. 


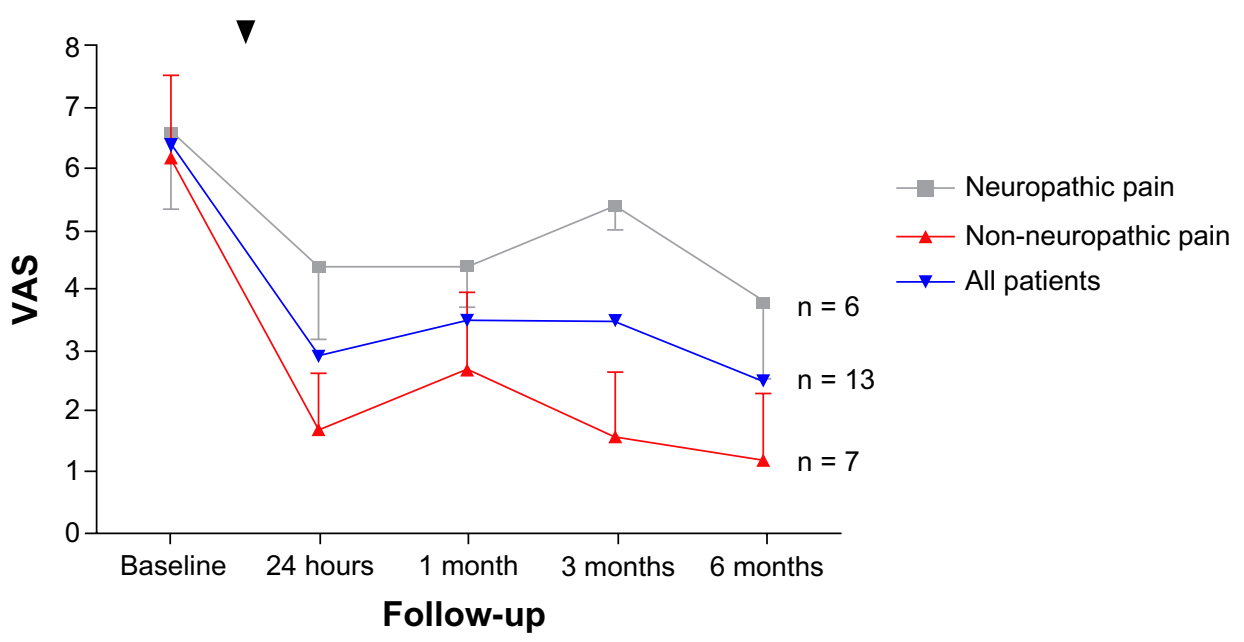

Figure 3 Median visual analog scale (VAS) scores in the leg region according to the time of evaluation before and after the procedure ( $\nabla)$.

Notes: There was significant difference between the groups only at 3 months $(P=0.006)$. Both groups improved significantly, with best results toward the end of follow-up.

pain relief of more than 6 months. Eight observational studies were included in the systematic review and four randomized trials in the meta-analysis. The indicated level of evidence for long-term pain relief was II-3 for ozone therapy applied intradiscally and II-1 for ozone therapy applied paravertebrally. The grading of recommendation was $1 \mathrm{C}$ for intradiscal ozone therapy and 1B for paravertebral ozone therapy. ${ }^{9}$

At the beginning of this study, there was no record in the literature about the use of ozone by epiduroscopy for treating lower back pain. Only recently have the first publications come out, showing positive results of this technique for treatment of low back pain. ${ }^{11,12}$ Masini and Calaça ${ }^{12}$ retrospectively studied 32 patients who failed to achieve significant response of at least 6 weeks of conservative treatment. After epiduroscopy associated with ozone and steroid injections, patients showed persistent improvement of $60 \%$. Alexandre et al ${ }^{11}$ published results of a retrospective analysis in patients with FBSS undergoing endoscopic adhesiolysis with intradiscal procedure (named percutaneous peridurodiscolysis), also with positive results.

Other retrospective studies using ozone injections in other sites in heterogeneous populations, with different follow-up periods and some discrepancy in the CT or MRI evaluations of morphological criteria, were also positive. Muto et $\mathrm{al}^{23,25}$ and Muto and Avella ${ }^{26}$ published three studies between 1998 and 2008 in which intradiscal injection of an oxygen-ozone mixture under CT guidance was used and reported an $80 \%$ success rate at short-term follow-up and a $75 \%$ success rate at long-term follow-up, with no major side effects.

There are also few retrospective studies reporting the exclusive inclusion of patients with FBSS. ${ }^{23,27-29}$ Oder et $\mathrm{al}^{28}$ studied 621 patients to determine associations among the morphology of the disc disease, patient-specific data, and treatment outcomes. Patients underwent CT-guided ozonucleolysis in combination with periradicular infiltration by steroids under local anesthesia. Based only on MRI image findings of the lumbar spine, the patients were retrospectively divided into five diagnosis groups: group I (bulging disc); group II (herniated disc); group III (FBSS); group IV (primarily intervertebral osteochondrosis); and group V, which contained 114 patients (other primary non-discal changes [inter-vertebral arthrosis, spinal canal stenosis, and pseudoanterolisthesis]). Each patient was monitored for a period of 6 months and documented with the ODI and VAS. Patients younger than 50 years had significantly better values on the VAS and in ODI scores 6 months after treatment. ${ }^{28}$

Accordingly, epiduroscopy seems to yield positive results when used in combination with therapeutic substances,

Table 2 Frequency of drug use for pain aid in patients at baseline before the procedure and 6 months after the ozone injection

\begin{tabular}{lllll}
\hline Drugs & \multicolumn{2}{l}{ Baseline } & \multicolumn{3}{l}{ 6 months } \\
\cline { 2 - 5 } & DN4 & DN4 & DN4 & DN4 \\
& score $<$ 4 & score $>$ 4 & score $<$ 4 & score $>$ 4 \\
\hline Triciclics antidepressants & $7 / 7$ & $6 / 6$ & $4 / 7$ & $4 / 6$ \\
Anticonvulsivants & $2 / 7$ & $\mathrm{I} / 6$ & $0 / 7$ & $0 / 6$ \\
Baclofen & $\mathrm{I} / 7$ & $0 / 6$ & $0 / 7$ & $0 / 6$ \\
NSAIDs & $5 / 7$ & $3 / 6$ & $\mathrm{I} / 7$ & $2 / 6$ \\
Muscle relaxant & $4 / 7$ & $2 / 6$ & $\mathrm{I} / 7$ & $\mathrm{I} / 6$ \\
Strong opioids & $2 / 7$ & $0 / 6$ & $0 / 7$ & $\mathrm{I} / 6$ \\
Weak opioids & $7 / 7$ & $5 / 6$ & $3 / 7$ & $4 / 6$ \\
Clorpromazine & $6 / 7$ & $6 / 6$ & $3 / 7$ & $4 / 6$ \\
\hline
\end{tabular}

Notes: Patients were divided into two groups based on DN4 classification system (ie, patients who had predominantly neuropathic pain components [DN4 scores $>4$ ] or predominantly non-neuropathic pain components [DN4 scores <4]). Overall, there was a decrease in the number of patients who needed oral medication as a complement for pain alleviation following the procedure.

Abbreviations: NSAIDs, nonsteroidal anti-inflammatory drugs; DN4, Douleur Neuropathique 4. 
including ozone, instilled in the epidural space. Such encouraging results concerning the use of ozone in the treatment of low back pain secondary to disc herniation have made us interested in starting a pilot study to address the question whether the combination of endoscopic adhesiolysis followed by instillation of ozone gas mixture would have any benefit in patients with refractory pain related to FBSS.

Recently, Paoloni et $\mathrm{al}^{30}$ conducted a multicenter, randomized, double-blind, "simulated therapy"-controlled clinical trial. Thirty-six patients received intramuscular-paravertebral ozone injections, whereas 24 patients received simulated lumbar intramuscular-paravertebral injections. Patients who received ozone had significantly lower pain scores than patients who received simulated therapy (61\% versus 33\%). Active ozone therapy was followed by a significantly lower number of days on nonsteroidal anti-inflammatory drugs, as well as a significant improvement on the disability scale in the patient study group compared to the control group.

A number of authors ${ }^{27-29}$ have used ozone combined with other substances such as corticosteroids and hyaluronidase or applied within the vertebral disc and in the intervertebral foramen in heterogeneous populations of patients with low back pain. Only Alexandre et $\mathrm{al}^{11}$ and Masini and Calaça ${ }^{12}$ have used spinal endoscopy to inject ozone into the epidural space. Both groups have shown positive results with ozone therapy. However, the different routes and sites of application of ozone, the heterogeneity of study groups, and different assessment tools used by these authors may lead to interpretation bias. Paoloni et $\mathrm{al}^{30}$ compared the application of ozone with a sham procedure in order to reduce these interpretation biases in evaluating patients with acute low back pain.

Although the present study is a pilot study, it differs from others because the population is homogenous (FBSS), the patients were carefully evaluated with classification of type of pain and exclusion of litigation, and ozone was applied by the same epidural route by spinal endoscopy. Furthermore, we rigorously evaluated the presence or absence of adverse events using international standardized criteria.

What remains unclear is the exact mechanism by which ozone acts in the treatment of low back pain. According to Bocci, ${ }^{31}$ the gas could have two mechanisms: mechanical and chemical adhesiolysis and shrinkage of disc content. When in contact with biological tissue, ozone dissolves in water and reacts immediately, generating a cascade of reactive oxygen species including $\mathrm{H}_{2} \mathrm{O}_{2}$ and possibly hydroxyl radicals that are more reactive. These molecules can react with carbohydrates and amino acids that make proteoglycans and collagen type I and II. ${ }^{8,32}$ Consequently, the reabsorption of water and hydrolytic products can lead to dehydration and, for example, progressive disappearance of the herniated disc material. The reduced mechanical irritation, decreases the sensitivity of axon terminals of neurons present in the disc annulus. ${ }^{33}$

Another possible action of ozone would be through the anti-inflammatory action over cytokines. ${ }^{34}$ There is evidence that a wide variety of substances, such as tumor necrosis factor- $\alpha$ and interleukins (IL-1 $\beta$, IL-6, and IL-8) may have an important role in the development of low back pain, whether irradiated or not, which would contribute to maintenance of the chronic low back pain. ${ }^{35}$ The peripheral sensitization can be prevented by ozone or mediators arising from its application. A recent study has shown strong evidence that proteins of low-molecular-weight, when ozonized, inhibit the nuclear factor-kappa $\beta$ and IRAK-1, which may decrease the immunological response. ${ }^{36}$ Furthermore, the oxidation of interleukins, interleukin receptors, and nuclear factors, promoted by ozone, could block the expression of COX-2 and its biochemical consequences along the pain pathway. Greater reduction of pain was observed in non-neuropathic pain components when compared to neuropathic pain itself. Considering that nociceptive (non-neuropathic) pain is related to chronic inflammation, it is likely that the antiinflammatory effect of ozone may be the main mediating mechanism of the therapy presented herein.

Ozone therapy for lumbar disc herniation is a procedure that is generally considered to have few or no adverse effects at concentrations used for therapeutic application $(10-40 \mu \mathrm{g} / \mathrm{mL}) .{ }^{31,37}$ Side effects and adverse events of ozone therapy involve three major clinical syndromes: vasovagal attack, syncope, and air embolism. Early on, the patient may experience sweating, paresthesias, abdominal pain, headache, bradycardia, dizziness, and thread pulse, among others. Later, there may be headache, dizziness, and visual disturbance, such as ephemeral scotomas. The symptoms may be early or late and are more frequently reported with systemic administration (autohemotransfusion). There is little documentation about the side effects of the administration of paravertebral ozone. ${ }^{20}$

As for spinal endoscopy, complications related to the procedure itself may include those arising from the drugs used during the procedure or caused by puncture trauma, accidental dural injury, puncture of an epidural blood vessel, or epidural bleeding. The symptoms associated with these complications may include headache, general back complaints, vomiting, meningitis, radicular radiating pain, bladder and rectal disorders, and even confusion. ${ }^{38}$ There are reports on an acute incident of bilateral blindness associated with preretinal, retinal, and 
subretinal hemorrhages following epiduroscopy. ${ }^{39,40}$ We did not observe any complications or side effects related to spinal endoscopy or epidural ozone injection in this study.

\section{Conclusion}

This report shows that application of ozone gas in the epidural space of patients with FBSS via spinal endoscopy is apparently safe and reveals a tendency toward positive effect, at least at a 6-month-follow-up, and especially in patients with non-neuropathic pain - even when chronic and otherwise refractory. The results suggest that epidural ozone might be a therapeutic option for persistent low back pain in the future, but controlled studies are still required to prove its efficacy.

\section{Acknowledgments}

The authors would like to acknowledge the collaboration of medical doctors and residents, nurses, and administration staff of the Pain Center and Division of Functional Neurosurgery of the Department of Neurology at USP, and the support of FAPESP grant \#2011/08529-5 and MCT/CNPq grant \#482365/2010-2.

\section{Disclosure}

The authors report no conflicts of interest in this work.

\section{References}

1. Manchikanti L, Singh V, Datta S, Cohen SP, Hirsch JA; American Society of Interventional Pain Physicians. Comprehensive review of epidemiology, scope, and impact of spinal pain. Pain Physician. 2009;12:E35-E70.

2. Currow DC, Agar M, Plummer JL, Blyth FM, Abernethy AP. Chronic pain in South Australia - population levels that interfere extremely with activities of daily living. Aust N Z J Public Health. 2010;34: 232-239.

3. Teixeira MJ, Yeng LT, Garcia OG, Fonoff ET, Paiva WS, Araujo JO. Failed back surgery pain syndrome: therapeutic approach descriptive study in 56 patients. Rev Assoc Med Bras. 2011; 57(3):282-287. English, Portuguese.

4. Elliott AM, Smith BH, Hannaford PC, Smith WC, Chambers WA. The course of chronic pain in the community: results of a 4-year follow-up study. Pain. 2002;99:299-307.

5. Enthoven P, Skargren E, Oberg B. Clinical course in patients seeking primary care for back or neck pain: a prospective 5-year follow-up of outcome and health care consumption with subgroup analysis. Spine (Phila Pa 1976). 2004;29:2458-2465.

6. Burton CV. Causes of failure of surgery on the lumbar spine: ten-year follow-up. Mt Sinai J Med. 1991;58(2):183-187.

7. Chan CW, Peng P. Failed back surgery syndrome. Pain Med. 2011 Apr;12(4):577-606.

8. Re L, Mawsouf MN, Menéndez S, León OS, Sánchez GM, Hernández F. Ozone therapy: clinical and basic evidence of its therapeutic potential. Arch Med Res. 2008;39(1):17-26.

9. Magalhaes FN, Dotta L, Sasse A, Teixeira MJ, Fonoff ET. Ozone therapy as a treatment for low back pain secondary to herniated disc: a systematic review and meta-analysis of randomized controlled trials. Pain Physician. 2012;15(2):E115-E129.

10. Anderson SR, Racz GB, Heavner J. Evolution of epidural lysis of adhesions. Pain Physician. 2000;3(3):262-270.
11. Alexandre A, Corò L, Paradiso R, et al. Treatment of symptomatic lumbar spinal degenerative pathologies by means of combined conservative biochemical treatments. Acta Neurochir Suppl. 2011;108:127-135.

12. Masini M, Calaça A. Minimally invasive treatment for refractory low back pain, targeted by epidural endoscopy with $\mathrm{O}_{2} / \mathrm{O}_{3}$ and steroid therapy. Acta Neurochir Suppl. 2010;108:33-37.

13. Hayek SM, Helm S, Benyamin RM, Singh V, Bryce DA, Smith HS. Effectiveness of spinal endoscopic adhesiolysis in post lumbar surgery syndrome: a systematic review. Pain Physician . 2009;12:419-435.

14. Fonoff ET, Lopez WO, de Oliveira YS, Lara NA, Teixeira MJ. Endoscopic approaches to the spinal cord. Acta Neurochir Suppl. 2011;108:75-84.

15. Bouhassira D, Attal N, Alchaar H, et al. Comparison of pain syndromes associated with nervous or somatic lesions and development of a new neuropathic pain diagnostic questionnaire (DN4). Pain. 2005;114(1-2): 29-36.

16. Attal N, Perrot S, Fermanian J, Bouhassira D. The neuropathic components of chronic low back pain: a prospective multicenter study using the DN4 Questionnaire. J Pain. 2011;12(10):1080-1087.

17. Vigatto R, Alexandre NM, Correa Filho HR. Development of a Brazilian Portuguese version of the Oswestry Disability Index: cross-cultural adaptation, reliability, and validity. Spine (Phila Pa 1976). 2007;32(4): $481-486$.

18. Santos JG, Brito JO, de Andrade DC, et al. Translation to Portuguese and validation of the Douleur Neuropathique 4 questionnaire. J Pain. 2010 May;11(5):484-490.

19. Manchikanti L, Saini B, Singh V. Spinal endoscopy and lysis of epidural adhesions in the management of chronic low back pain. Pain Physician. 2001;4:240-265.

20. Zambello A, Bianchi M, Bruno F. Sicurezza in ozonoterapia [Safety in ozone therapy]. Rivista Italiana di Ossigeno-Ozonoterapia. 2004;3: 25-34. Italian

21. Manchikanti L, Pampati V, Bakhit CE, Pakanati RR. Non-endoscopic and endoscopic adhesiolysis in post-lumbar laminectomy syndrome: a one-year outcome study and cost effectiveness analysis. Pain Physician. 1999;2(3):52-58.

22. Hussain A, Erdek M. Interventional pain management for failed back surgery syndrome. Pain Pract. Epub February 3, 2013.

23. Muto M, Ambrosanio G, Guarnieri G, et al. Low back pain and sciatica: treatment with intradiscal-intraforaminal $\mathrm{O}(2)-\mathrm{O}$ (3) injection. Our experience. Radiol Med. 2008;113(5):695-706. English, Italian.

24. Alexandre A, Zalaffi A. Electromyographic analysis of the outcome of lumbar disc herniation treated by intradiscal oxygen-ozone gas mixture injection. International Journal of Ozone Therapy. 2008;7:21-24.

25. Muto M, Andreula C, Leonardi M. Treatment of herniated lumbar disc by intradiscal and intraforaminal oxygen-ozone $\left(\mathrm{O}_{2}-\mathrm{O}_{3}\right)$ injection. J Neuroradiol. 2004;31(3):183-189.

26. Muto M, Avella F. Percutaneous treatment of herniated lumbar disc by intradiscal oxygen-ozone injection. Interv Neuroradiol. 1998;4: 279-286.

27. Fabris G, Tommasini G, Petralia B, et al. Iaiza. L'ossigeno-ozono terapia intra-foraminale. Rivista di Neuroradiologia. 2001;14(Suppl 1):61-66. Italian.

28. Oder B, Loewe M, Reisegger M, Lang W, Ilias W, Thurnher SA. CT-guided ozone/steroid therapy for the treatment of degenerative spinal disease - effect of age, gender, disc pathology and multi-segmental changes. Neuroradiology. 2008;50(9):777-785.

29. Cinnella P, Brayda-Bruno M. La nostra esperienza nel trattamento dei conflitti disco-radicolari e delle radicolopatie post-chirurgiche con ossigeno-ozono terapia infiltrativa paravertebrale [Our experience in treating disc-root compression and post-surgical radiculopathies with paraspinal oxygen-ozone injection]. Neuroradiol J 2001;14(Suppl 1):75-79. Italian.

30. Paoloni M, Di Sante L, Cacchio A, et al. Intramuscular oxygen-ozone therapy in the treatment of acute back pain with lumbar disc herniation: a multicenter, randomized, double-blind, clinical trial of active and simulated lumbar paravertebral injection. Spine (Phila Pa 1976). 2009;34(13):1337-1344. 
31. Bocci VA. Scientific and medical aspects of ozone therapy. State of the art. Arch Med Res. 2006;37(4):425-435.

32. Bocci VPR, Corradeschi F, Busi E, Cervelli C, Bocchi Land BR. Oxygen-ozone in orthopaedics: EPR detection of hydroxyl free radicals in ozone-treated "nucleus pulposus" material. Neuroradiol $J$ 2001b;14:55-59.

33. Alexandre A, Corò L, Azuelos A, et al. Intradiscal injection of oxygenozone gas mixture for the treatment of cervical disc herniations. Acta Neurochir Suppl. 2005;92:79-82.

34. Souza YM, Fontes B, Martins JO, et al. Evaluation of the effects of ozone therapy in the treatment of intra-abdominal infection in rats. Clinics (Sao Paulo). 2009;65(2):195-202.

35. Re L, Martínez-Sánchez G, Malcangi G, Mercanti A, Labate, V. Ozone therapy: a clinical study on pain management. International Journal of Ozone Therapy. 2008;7:37-44.
36. Cappello C, Saugel B, Huth KC, et al. Ozonized low density lipoprotein (ozLDL) inhibits NF-kappaB and IRAK-1-associated signaling. Arterioscler Thromb Vasc Biol. 2007;27(1):226-232.

37. Steppan J, Meaders T, Muto M, Murphy KJ. A metaanalysis of the effectiveness and safety of ozone treatments for herniated lumbar discs. J Vasc Interv Radiol. 2010;21:534-548.

38. Schütze G. Epiduroscopy: Spinal Endoscopy. Berlin: Springer Verlag; 2008:118-121.

39. Amirikia A, Scott IU, Murray TG, Halperin LS. Acute bilateral visual loss associated with retinal hemorrhages following epiduroscopy. Arch Ophthalmol. 2000;118(2):287-289.

40. Gill JB, Heavner JE. Visual impairment following epidural fluid injections and epiduroscopy: a review. Pain Med. 2005;6(5):367-374.

\section{Publish your work in this journal}

Neuropsychiatric Disease and Treatment is an international, peerreviewed journal of clinical therapeutics and pharmacology focusing on concise rapid reporting of clinical or pre-clinical studies on a range of neuropsychiatric and neurological disorders. This journal is indexed on PubMed Central, the 'PsycINFO' database and CAS.
The manuscript management system is completely online and includes a very quick and fair peer-review system, which is all easy to use. Visit http://www.dovepress.com/testimonials.php to read real quotes from published authors. 